\title{
Analisis terhadap Diversitas Top Manajeman Tim (TMT) pada BUMN Holding di Indonesia
}

\author{
Erwin Pemana $^{\left.1^{*}\right)}$, Bambang Purwoko ${ }^{2)}$, Sri Widyastuti ${ }^{3)}$, Widarto Rachbini $^{4)}$, Achsanul Qosasi ${ }^{\text {(5) }}$ \\ ${ }^{1 *, 3}$ Fakultas Ekonomi dan Bisnis Universitas Pancasila \\ ${ }^{2,4)}$ Sekolah Pasca Sarjana Universitas Pancasila \\ ${ }^{5}$ Fakultas Ekonomi dan Bisnis Universitas Airlangga Surabaya \\ e-mail: win.buyung@ gmail.com ${ }^{1 *}$
}

\begin{abstract}
Abstrak
Penelitian ini bertujuan untuk menganalisis keragaman Top Management Team (TMT) pada BUMN Holding di Indonesia dengan menggunakan dimensi demografi sederhana dan demografi relasional yang meliputi jenis kelamin, usia, etnik, masa jabatan, pendidikan formal dan pengalaman fungsional. Teknik analisis menggunakan Structural Equetion Model (SEM) with SmartPLS.Jumlah sample sebanyak 40 perusahaan yang telah bergabung menjadi 4 BUMN Holding di Indonesia. Responden penelitian adalah para direktur perusahaan, satu perusahaan diwakili oleh satu direktur. Hasil penelitian menunjukkan bahwa jenis kelamin menjadi satu-satunya dimensi yang tidak signifikan dalam membentuk TMT Diversity BUMN Holding di Indonesia. Implikasinya, pada kasus BUMN Holding, tidak menjadi persoalan jika komposisi TMT jenis kelamin seragam. Sedangkan yang harus beragam adalah dimensi yang signifikan yakni usia, etnik, masa jabatan, pendidikan formal dan pengalaman fungsional. Mengingat pentingnya peran BUMN dalam proses pembangunan nasional, maka diperlukan kajian lanjutan pada objek yang sama dengan lokus penelitian seluruh level manajemen.
\end{abstract}

Kata kunci: BUMN Holding dan keragaman TMT.

\begin{abstract}
This study aims to analyze the diversity of the Top Management Team (TMT) in SOE Holding in Indonesia using both dimensions, simple demographic and relational demographics which include gender, age, ethnicity, tenure, formal education and functional experience. The analysis technique uses Structural Equetion Model (SEM) with SmartPLS. The number of samples as many as 40 companies have joined to become 4 BUMN Holding in Indonesia. Research respondents are company directors, one company is represented by one director. The results showed that gender was the only insignificant dimension in shaping TMT Diversity BUMN Holding in Indonesia. The implication, in the case of BUMN Holding, is not a problem if the composition of TMT is of uniform sex. While that must vary is a significant dimension namely age, ethnicity, tenure, formal education and functional experience. Given the important role of SOEs in the national development process, further studies are needed on the same object as the research locus at all levels of management.
\end{abstract}

Keywords: BUMN Holding and TMT diversity. 


\section{PENDAHULUAN}

Untuk mencapai tujuan BUMN sebagai agen pembangunan yang efisien dan efektif, maka pemerintah melakukan sinergitas dan konsolidasi BUMN melalui pembentukan holding BUMN. Pemerintah melakukan penggabungan BUMN-BUMN di sektor yang sama menjadi beberapa holding. Pemikiran yang mendasari pembentukan holding BUMN ini adalah untuk optimalisasi manajemen, efektifitas dan efisiensi biaya. Jika beberapa BUMN di sektor yang sama dijadikan holding maka akan ada share support di dalam holding tersebut, misalkan human capital, distribution, information communication and technology dan sebagainya (Renstra Deputi ELKP, 2015-2019). Komposisi Top Manejemen Tim (TMT) merupakan kunci sukses BUMN Holding untuk meralisasikan tujuan tersebut.

Manajemen puncak perusahaan merupakan sumberdaya internal yang juga menjadi penentu kinerja perusahaan. (Gallén, 2009) menerangkan TMT memiliki peran yang sangat besar dalam proses keberhasilan perusahaan. TMT merupakan tim manajemen di tingkat atas yang mengarahkan perusahaan secara keseluruhan dan mengkoordinasi semua fungsi utama sehingga cita-cita perusahaan dapat tercapai (Gallén, 2009).

Sejalan dengan Upper Echelon Theory yang dikemukakan oleh (Hambrick, 2016) yang menyatakan bahwa pilihan-pilihan yang diambil oleh organisasi seperti pilihan strategis dan implementasi strategi ditentukan oleh orang-orang yang memiliki peran besar dalam organisasi, yaitu para manager atau pimpinannya. Pilihan strategis yang diambil oleh pimpinan tersebut akhirnya akan menentukan kinerja organisasi itu sendiri.

TMT di beberapa organisasi perusahaan terdiri dari beberapa individu yang bertanggung jawab terhadap kepemimpinan dan fungsi-fungsi manajemen suatu organsasi. Elemen manusia pada TMT dapat mempengaruhi kesuksesan dan kelangsungan organisasi bisnis. Dari sisi social capital aspek fundamental pada perusahaan terletak pada manajemen puncaknya. Para direktur akan menggunakan jaringan kerja yang dimiliki untuk menjaga agar perusahaan selalu up to date dengan praktek-praktek dan prosedur-prosedur di berbagai perusahaan lainnya (Camelo, et al, 2017).

Hambrick (2016) juga menjelaskan bahwa terkadang pemimpin puncak akan menerima informasi dengan jumlah yang sangat banyak yang melebihi kemampuan mereka untuk menggunakan informasi-informasi tersebut sebagai dasar untuk pengambilan keputusan, sehingga pemimpin akan cenderung menyaring informasi yang penting berdasarkan batasan rasional mereka. Dalam penyaringan informasi ini, batasan rasionalitas seperti batasan kognitif, nilai, pengalaman dan keyakinan akan menjadi dasar bagi pemimpin untuk asumsi atau persepsi atas informasi-informasi tersebut. Kemudian, setelah melalui penyaringan tersebut informasi akan diinterpretasikan menjadi persepsi manajerial dan keputusan strategis akan diambil berdasarkan persepsi manajerial ini. Keputusan yang diambil inilah yang kemudian akan menentukan pertumbuhan perusahaan sehingga dapat dikatakan bahwa pemimpin memiliki peran yang sangat penting dalam perusahaan (P.-Y. Li, 2017). 
Proses pengambilan keputusan terdiri dari beberapa tahapan yang sistematis dan proses kompleks yang melibatkan interaksi antar pemimpin puncak (Ling, et al, 2015). Kompleksitas dalam proses pengambilan keputusan tersebut dapat memunculkan ambiguitas karena sekumpulan pemimpin organisasi memiliki heterogenitas dalam hal nilai, keyakinan, kognitif atau perbedaan karakteristik lainnya (Finkelstein, et al, 2009). Untuk mengatasi permasalahan ini, para pemimpin harus melakukan kerjasama yang efektif dalam mereduksi efek negatif dan mengambil manfaat dari heterogenitas dalam bentuk keragaman Top Management Team (TMT) (Finkelstein et al., 2009).

TMT belum dapat disebut memiliki keputusan yang berkualitas dan berkinerja hingga secara efektif mampu menyelenggarakan pertukaran informasi yang kaya, cepat dan akurat, sikap kerjasama, keikutsertaan dalam pengambilan keputusan strategis dan aksi integritas. Terkait dengan ini maka menarik dilakukan kajian terhadap TMT diversity yang dapat digunakan untuk menentukan komposisi TMT pada BUMN Holding. Mengingat BUMN memiliki posisi yang sangat strategis dalam perekonomian di Indonesia.

\section{TINJAUAN PUSTAKA}

Beberapa studi tentang TMT berfokus pada kontribusi kepemimpinan dalam persepektif individual atau manajer terhadap organisasinya. Seiring dengan perkembangan ilmu pengetahuan dalam disiplin ilmu TMT, para peneliti percaya bahwa karakteristik individual seperti usia, masa jabatan, jenis kelamin, status sebagai orang dalam atau orang luar perusahaan, merupakan determinan faktor keputusan dan nilai managerial (Park \& Cho, 2014). Pemahaman keterkaitan tentang antara karakteristik managerial dan keputusan strategis sangat penting untuk membangun teori manajemen.

Pendekatan ini memperkirakan sejauh mana seseorang berbeda dari individu lain atau kelompok sehubungan dengan variabel demografi (misalnya jenis kelamin, usia, ras, masa kerja) dan memeriksa bagaimana perbedaan ini mempengaruhi sikap dan perilaku individu. Keterkaitan demografi dibangun berdasarkan paradigma kesamaan daya tarik dan teori kategorisasi diri. Di antaranya, teori kategorisasi diri mengusulkan bahwa orang dapat menggunakan karakteristik sosial seperti usia, jenis kelamin, ras, pendidikan, atau keanggotaan organisasi untuk menentukan kelompok psikologis dan untuk mempromosikan identitas diri yang positif.

Yang dan Wang (2014) dalam studinya mengeksplorasi hubungan antara Keragaman karakteristik TMT baik dari demografi sederhana dan demografi relasional yakni usia, jenis kelamin, latar belakang pendidikan dan pengalaman fungsional, masa kerja dan etnik (Yang \& Wang, 2014). Berikut dijabarkan indikator-indikator Keragaman Karakteristik TMT:

Usia merupakan indikator yang penting karena dapat membantu memprediksi pengalaman kerja individu. Orang-orang dengan usia yang sama memiliki pengalaman serupa, yang mengarah ke sikap dan keyakinan bersama. Keragaman usia diharapkan dapat meningkatkan berbagai perspektif tentang isu-isu strategis menghadapi suatu perusahaan, sehingga merangsang pertimbangan perubahan. 
Dengan demikian, usia seseorang diharapkan mempengaruhi perspektif pengambilan pilihan keputusan strategis dan.

Jenis kelamin. Manajemen dan literatur psikologi sosial menyarankan bahwa manajer senior pria dan wanita berperilaku berbeda, dan dapat mempengaruhi strategi perusahaan secara berbeda (Gagliarducci \& Paserman, 2014). Bahkan, ada banyak perbedaan antara eksekutif laki-laki dan perempuan tentang niat entrepreneurial serta karakteristik dan perilaku. Karakteristik dan kinerja usaha mereka dalam konteks transisi membedakan antara efek jender langsung dan tidak langsung (Jurkus, et al, 2011). Perbedaan gender di antara tim eksekutif mempengaruhi biaya agensi karena perusahaan dengan proporsi eksekutif pria yang lebih tinggi membutuhkan lebih banyak arus kas untuk keputusan strategis investasi (Jurkus et al., 2011). Lebih jauh lagi, eksekutif pria dan wanita merasakan risiko secara berbeda, dan khususnya eksekutif laki-laki lebih proaktif, lebih tertarik pada risiko, dan lebih mungkin menunjukkan kepercayaan berlebihan (P.-Y. Li, 2017). Dengan demikian, eksekutif laki-laki lebih berani dan menerapkan kegiatan strategis wirausaha yang relatif lebih agresif (Yang \& Wang, 2014).

Latar Belakang Pendidikan. Perspektif upper echelon yang diajukan oleh Hambrick (2016) menunjukkan bahwa latar belakang pendidikan formal dapat mencerminkan kemampuan manajer dan basis keterampilan. Penelitian sebelumnya menunjukkan pengaruh unik yang terkait dengan pendidikan Top Manajemen. Artinya, latar belakang pendidikan mempengaruhi proses pengambilan keputusan strategis dan kinerja. Dalam penelitian Yang \& Wang, (2014), fokus pada heterogenitas spesialisasi pendidikan untuk mempertimbangkan pengaruh pendidikan. Hasilnya, latar belakang pendidikan merupakan bagian dari variabel strategis pada top leader untuk membentukkinerja perusahaan.

Pengalaman fungsional. Meskipun hubungan antara latar belakang fungsional eksekutif puncak dan arahan organisasi belum ditetapkan, bukti empiris memvalidasi keberadaan pola asosiasi antara latar belakang fungsional dan strategi pada tingkat bisnis (Yang \& Wang, 2014). Selanjutnya, penelitian empiris juga menemukan heterogenitas latar belakang fungsional atau keragaman dalam pengalaman fungsional berhubungan secara positif dengan adaptasi dan perubahan strategi. Heterogenitas latar belakang fungsional dapat membawa keterampilan teknis, hukum, dan manajemen TMT dan kemampuan untuk membentuk perspektif baru dan informasi yang beragam. Kombinasi heterogenitas latar belakang fungsional membawa ide-ide baru untuk mencegah pemikiran yang bersifat jangka pendek, meningkatkan kemampuan pemecahan masalah yang inovatif dan memecahkan masalah kompleks yang tidak standar.

Tenure. Peningkatan masa kerja dikaitkan dengan stabilitas, berkurangnya konflik dan komunikasi yang unggul (Camelo, et al., 2017). Selain itu, (Ling et al., 2015) mengemukakan bahwa masa kerja yang lebih lama pada tim manajemen puncak dapat dikaitkan dengan kohesi sosial dan struktur kognitif bersama. Atribut tim ini dapat meningkatkan sosialisasi dan mengarah pada kinerja perusahaan yang lebih baik. Eksekutif yang melayani bersama untuk periode waktu yang lama 
mungkin cenderung mengembangkan pandangan yang sama karena akulturasi jangka panjang dari anggota tim dapat mengarah pada perspektif umum atau paradigma perusahaan (Hitt, et al, 2016). Namun, karena sifat kompleks dan tidak pasti dari keputusan diversifikasi internasional, pemahaman bersama tentang lingkungan internasional menjadi sangat penting. Eksekutif dengan masa kerja yang lebih lama di tim manajemen puncak dapat mengembangkan struktur kognitif bersama yang lebih akurat tentang lingkungan baru. Selain itu, masa kerja yang lebih lama dapat memberikan kesempatan bagi anggota tim untuk menilai dengan lebih baik kapabilitas perusahaan yang sesuai untuk diversifikasi bisnis baik skala lokal maupun global.

Etnis. Keragaman etnis sangat relevan dalam dunia yang semakin mengglobal. Perusahaan multinasional sering menjadi staf tim internasional dan populasi lokal - terutama di kota-kota besar menjadi lebih campuran dan multikultural. Keragaman etnis adalah fakta kehidupan saat ini dan etnis minoritas dalam populasi Barat meningkat tajam. Di Amerika Serikat, misalnya, jumlah minoritas diperkirakan akan meningkat dari sekitar sepertiga menjadi sekitar mayoritas pada 2042 (Bakas, 2017).Keragaman etnis menyiratkan heterogenitas dalam bahasa, agama, ras dan budaya. Keragaman etnis akan menguntungkan kinerja tim karena kumpulan keterampilan dan pengetahuan yang lebih beragam yang mengarah ke pelengkap dan pembelajaran bersama. Misalnya, karena saling melengkapi dan kesempatan belajar, tim yang beragam secara etnis dikaitkan dengan lebih banyak kreativitas dan inovasi (Bakas, 2017). Secara keseluruhan, keragaman etnis merupakan sumber heterogenitas yang penting.

Penelitian ini berusaha mengkonfirmasi dimensi penyusun variable utama penelitian yakni diversitas TMT. Sehingga variable diversitas dalam penelitian menjadi variable mandiri sehingga tidak mempunyai hipotesis penelitian. Dimensi diversitas TMT yang diadopsi penelitian ini yakni dimensi demografi sederhana dan demografi relasional. Indikator-indikator yang digunakan antara lain gender, age, tenure, ethnicity, functional background dan formal education (Wang \& Wang, 2014).

Sedangkan keragaman yang diajukan oleh (Harrison \& Klein, 2007) yakni keragaman variasi, disparitas dan sebaran tidak relevan untuk mengukur TMT diversity yang dimasud dalam penelitian ini dalam konteks penelitian BUMN holding. Sebab, unit analisis hanya pada satu level yakni level manajemen yakni TMT, tidak menyebar dan tidak bervariasi. Sehingga lebih tepat jika keberagaman TMT didekati dengan demografi sederhana dan demografi relasional (Wang, \& Wang, 2014) dan didukung oleh beberapa pakar sebelumnya yang juga menggunakan pendekatan demografi dalam mangukur TMT diversity (Certo, Lester, Dalton, \& Dalton, 2006; Kilduff, Angelmar, \& Mehra, 2000; van Knippenberg, Dawson, West, \& Homan, 2011).

\section{METODE PENELITIAN}

\section{Desain dan Waktu Penelitian}

Penelitian ini merupakan penelitian kuantitatif. Penelitian kuantitatif adalah pendekatan untuk menguji teori objektif dengan menganalisis variable yang pada gilirannya dapat diukur dengan 
menggunakan instrument data numeric dan dapat dianalisis menggunakan prosedur statistic (Creswell, 2014). Waktu penelitian dilakukan dari bulan Juni hingga Agustus 2019.

\section{Populasi Dan Sampel}

Populasi penelitian adalah seluruh entitas bisnis perusahaan yang sudah tergabung menjadi Holding BUMN di Indonesia sebanyak 45 entitas. Teknik pengambilan sampel yang digunakan adalah sensus, sebab semua anggota populasi menjadi sampel penelitian. Sebagaimana dinyatakan (Sugiyono, 2010) sensus adalah teknik penentuan sampel bila semua anggota populasi digunakan sebagai sampel. Istilah lain sensus adalah sampling jenuh. Penelitian ini menganalisis fenomena empirik tentang pengaruh TMT pada BUMN yang sudah menjadi holding. Ada 4 Holding BUMN yang akan dijadikan lokus penelitian yakni PT. Pupuk Indonesia Holding Company, PT. Cement Indonesia, PT. Perkebunan Nusantara dan PT. Perhutani. Jumlah total seluruh entitas bisnis pada empat BUMN Holding tersebut sebanyak 45 entitas yakni:

Tabel 1. Responden Penelitian

\begin{tabular}{|c|c|c|c|}
\hline No & Holding & No & Entitas Anak \\
\hline \multirow[t]{9}{*}{1} & \multirow{9}{*}{$\begin{array}{l}\text { PT. Pupuk Indonesia Holding } \\
\text { Company }\end{array}$} & 1 & PT. Pupuk Sriwidjaja Palembang \\
\hline & & 2 & PT. Petrikomia Gresik \\
\hline & & 3 & PT. Pupuk Kujang \\
\hline & & 4 & PT. Pupuk Kalimantan Timur \\
\hline & & 5 & PT. Pupuk Iskanda Muda \\
\hline & & 6 & PT. Rekayasa Industri \\
\hline & & 7 & PT. Mega Eltra \\
\hline & & 8 & PT. ASEAN Aceh Fertilizer \\
\hline & & 9 & Hengam Petrochemical Company \\
\hline \multirow[t]{17}{*}{2} & \multirow[t]{17}{*}{ PT. Semen Indonesia } & 10 & PT. Semen Padang \\
\hline & & 11 & PT. Semen Tonasa \\
\hline & & 12 & PT. Semen Gresik \\
\hline & & 13 & TLCC \\
\hline & & 14 & PT. Semen Indonesia Aceh \\
\hline & & 15 & PT. Semen Kupang Indonesia \\
\hline & & 16 & PT. Semen Indonesia Beton \\
\hline & & 17 & PT. Semen Indonesia Industri Bangunan \\
\hline & & 18 & PT. SGG Energi Prima \\
\hline & & 19 & PT. Semen Indonesia Internasional \\
\hline & & 20 & PT. Sinergi Informatika Semen Indonesia \\
\hline & & 21 & PT. Semen Indonesia Logistik \\
\hline & & 22 & PT. Kawasan Industri Gresik \\
\hline & & 23 & PT. Industri Kemasan Semen Gresik \\
\hline & & 24 & United Traktor Semen Gresik \\
\hline & & 25 & PT. Krakatau Semen Indonesia \\
\hline & & 26 & PT. Swadaya Graha \\
\hline \multirow[t]{2}{*}{3} & \multirow[t]{2}{*}{ PT. Perhutani } & 27 & PT. Inhutani I \\
\hline & & 28 & PT. Inhutani II \\
\hline
\end{tabular}


4. PT. Perkebunana Nusantara

\begin{tabular}{ll}
29 & PT. Inhutani III \\
\hline 30 & PT. Inhutani IV \\
\hline 31 & PT. Inhutani V
\end{tabular}

\begin{tabular}{ll}
32 & PTPN I \\
\hline 33 & PTPN II \\
\hline 34 & PTPN III \\
\hline 35 & PTPN IV \\
\hline 36 & PTPN V \\
\hline 37 & PTPN VI \\
\hline 38 & PTPN VII \\
\hline 39 & PTPN VIII \\
\hline 40 & PTPN IX \\
\hline 41 & PTPN X \\
\hline 42 & PTPN XI \\
\hline 43 & PTPN XII \\
\hline 44 & PTPN XIII \\
\hline 45 & PTPN XIV
\end{tabular}

Sumber: Diolah peneliti (2019)

\section{Teknik Analisis Data}

Penelitian ini menggunakan teknik analisis Structural Equation Model (SEM) dengan software smartPLS. SEM smartPLS dapat digunakan untuk melakukan analisis confirmatory (Ghozali, 2014). Analisis faktor confirmatori (CFA) merupakan teknik statistik yang digunakan untuk menemukan bentuk konstruk dari kumpulan variabel manifes, atau menguji suatu variabel atas asumsi manifes yang membangunnya (Imam. Ghozali, 2011). Sehingga analisis confirmatori sangat cocok untuk mengujikan suatu teori variabel atas manifes atau indikator-indikator yang membangunnya, dimana variabel tersebut diasumsikan hanya dapat diukur dengan indikator-indikator tersebut. Dimensi tersebut di turunkan menjadi Kuesioner penelitian sebagai berikut:

Tabel 2. Kuesioner Penelitian

\begin{tabular}{|c|c|c|c|c|c|c|}
\hline \multirow[t]{2}{*}{ No } & \multirow[t]{2}{*}{ Pernyataan } & \multicolumn{5}{|c|}{ Bobot } \\
\hline & & 1 & 2 & 3 & 4 & 5 \\
\hline \multicolumn{7}{|c|}{ Diversitas Top Management Team (TMT) } \\
\hline \multicolumn{7}{|c|}{ Gender } \\
\hline 1 & $\begin{array}{l}\text { Komposisi gender pada TMT memiliki proporsi yang } \\
\text { seimbang antara laki-laki dan perempuan. }\end{array}$ & & & & & \\
\hline 2 & $\begin{array}{l}\text { Diversitas gender pada TMT tercermin pada keberanian } \\
\text { mengambil keputusan strategis perusahaan }\end{array}$ & & & & & \\
\hline \multicolumn{7}{|c|}{ o } \\
\hline 3 & Komposisi usia TMT sangat beragam & & & & & \\
\hline 4 & TMT memiliki komposisi usia yang relative muda & & & & & \\
\hline 5 & $\begin{array}{l}\text { Diversitas usia TMT tercermin pada nilai dan topik } \\
\text { diskusi yang diajukan. }\end{array}$ & & & & & \\
\hline \multicolumn{7}{|c|}{ Tenure } \\
\hline 6 & Masa jabatan direktur sangat beragam & & & & & \\
\hline
\end{tabular}




\begin{tabular}{ll}
\hline 7 & $\begin{array}{l}\text { Komposisi Level Pendidikan formal TMT sangat } \\
\text { beragam }\end{array}$ \\
\hline 8 & $\begin{array}{l}\text { Komposisi pendidikan formal TMT berasal dari } \\
\text { perguruan tinggi yang beragam }\end{array}$ \\
\hline 9 & $\begin{array}{l}\text { Komposisi pendidikan formal TMT berasal dari bidang } \\
\text { studi yang beragam }\end{array}$ \\
\hline Ethnic & $\begin{array}{l}\text { TMT berasal dari berbagai etnik/ suku berbeda di } \\
\text { Indonesia }\end{array}$ \\
\hline 10 & $\begin{array}{l}\text { TMT yang berasal dari satu daerah yang sama memiliki } \\
\text { interaksi yang lebih intensive dibanding dengan TMT } \\
\text { yang berasal dari daerah yang berbeda }\end{array}$ \\
\hline Fungsional Background \\
\hline 12 & $\begin{array}{l}\text { TMT terdiri dari orang-orang yang memiliki latar } \\
\text { belakang pengalaman yang berbeda-beda }\end{array}$ \\
\hline 13 & $\begin{array}{l}\text { TMT terdiri dari orang-orang yang memiliki masa kerja } \\
\text { yang beragam }\end{array}$ \\
\hline 14 & $\begin{array}{l}\text { Perbedaan latar belakang tercermin pada proses } \\
\text { pengambilan keputusan strategis perusahaan }\end{array}$ \\
\hline Sumb : Diblah oleh peneliti (2019)
\end{tabular}

Sumber: Diolah oleh peneliti (2019)

Kuesioner dikirim ke semua perusahaan yang tergabung menjadi holding BUMN. Dari 45 berkas kuesioner yang dikirimkan, ada sebanyak 40 berkas yang kembali dan diisi oleh para direktur. Artinya, parsentase pengembalian kuesioner mencapat $89 \%$.

Analisis yang digunakan adalah analisis konfirmatory dengan menggunakan model persamaan struktural (Structural Equation Modelling - SEM) with smartPLS. Partial Least Squares (PLS) digunakan untuk menguji data yang diperoleh dari 40 responden, (Chin, 1998). Data dianalisis dengan SmartPLS 2.0 yang dikembangkan oleh (Ringle \& Wende, S. Will, 2005). SmartPLS 2.0 digunakan dengan pertimbangan bahwa SmartPLS 2.0 dikembangkan berdasarkan jalur pemodelan dan bootstrap, dan direkomendasikan oleh (Tenenhaus \& Esposito, 2005)dan (Wetzels, Odekerken-Schroder, \& van Oppen, 2009). Model penelitian yang dikembangkan adalah model reflektif. Tujuan model refektif adalah analisis data, dimana peneliti lebih lanjut dapat mengkonfirmasi hasil analisis berdasarkan teori yang sudah dibangun dan data kuesioner yang sudah diperoleh.

\section{HASIL PEMBAHASAN}

Penelitian ini menggunakan teknik analisis Structutal Equetion Model (SEM)withPartial Least Square (PLS).Analisis SEM with PLS dilakukan dengan tiga tahap yakni analisis outer model, analisis inner model, dan pengujian hipotesis.

\section{Analisis Outer Model}

Berikut disajikan tabel analisis terhadap outer model penelitian: 
JURNAL MANAJEMEN DAN KEUANGAN, VOL 8, NO 3, DESEMBER 2019

Tabel 3. Cronbach Alpha, Composite Reliability Dan Average Variance Axtracted

\begin{tabular}{|c|c|c|c|c|c|c|c|c|c|}
\hline & $\begin{array}{l}\text { Cut } \\
\text { Off }\end{array}$ & Age & Ethnic & $\begin{array}{c}\text { Formal } \\
\text { education }\end{array}$ & $\begin{array}{c}\text { Functional } \\
\text { Background }\end{array}$ & Gender & $\begin{array}{c}\text { TMT } \\
\text { Diversity }\end{array}$ & Tenure & Ket \\
\hline $\begin{array}{l}\text { Cronbach's } \\
\text { Alpha }\end{array}$ & $>0.6$ & 0.60 & 0,70 & 0,71 & 0,68 & 0,77 & 0.78 & 0,61 & $\begin{array}{c}\text { Semua } \\
\text { aspek }\end{array}$ \\
\hline $\begin{array}{l}\text { Composite } \\
\text { Reliability }\end{array}$ & $>0.7$ & 0.80 & 0.73 & 0.84 & 0.83 & 0.90 & 0.83 & 0.71 & $\begin{array}{c}\text { memenu } \\
\text { hi }\end{array}$ \\
\hline $\begin{array}{l}\text { Average } \\
\text { Variance } \\
\text { Extracted } \\
(A V E)\end{array}$ & $>0.5$ & 0.68 & 0.59 & 0.63 & 0.63 & 0.82 & 0.52 & 0.57 & standar \\
\hline
\end{tabular}

Sumber: Output SmartPLS 3.0 (2019).

Menurut Ghozali (2014), u ntuk uji reliabilitas konstruk diukur dengan composite reliability dan cronbach's alpha. Konstruk dinyatakan reliabel jika memiliki nilai composite reliability di atas 0,70dan cronbach's alpha di atas 0,60. Sedangkan nilai average variance extracted (AVE) yang memadai untuk mengukur validitas adalah sebesar 0,5. Berdasarkan kriteria tabel 3 maka output olah data menunjukkan hasil semua kriteria outer model terpenuhi sehingga dapat disimpulkan bahwa data penelitian memiliki validitas dan realibilitas yang baik, oleh karena itu bisa dilanjutkan ke analisis inner model.

\section{Analisis Inner Model}

Analisa inner model/analisa struktural model dilakukan untuk memastikan bahwa model struktural yang dibangun robust dan akurat. Regresi robust merupakan metode regresi yang digunakan pada saat data berdistribusi error tidak normal atau adanya beberapa outlier yang berpengaruh pada model (Ghozali, 2014). Metode ini merupakan alat penting untuk menganalisa data yang dipengaruhi oleh outlier sehingga dihasilkan model yang resisten terhadap outlier.Suatu estimasi yang resisten adalah yang tidak terpengaruh oleh perubahan besar pada bagian kecil data atau perubahan kecil pada bagian besar data.

Evaluasi inner model dapat dilihat dari beberapa indikator yang meliputi; koefisien determinasi $\left(\mathrm{R}^{2}\right)$; Predictive Relevance $\left(\mathrm{Q}^{2}\right)$; Goodness of Fit Index (GoF).Berikutdisajikan perhitugan untuk masing-masing indicator.

1. Koefisien Determinasi $\left(\mathrm{R}^{2}\right)$

Berikut disajikan nilai $\mathrm{R}^{2}$ output software smartPLS 3

Tabel 4. Nilai $\mathbf{R}^{2}$

\begin{tabular}{|c|c|c|}
\hline & R Square & R Square Adjusted \\
\hline Age & 0.59 & 0.58 \\
\hline Ethnic & 0.51 & 0.50 \\
\hline Formal education & 0.78 & 0.78 \\
\hline Functional Background & 0.66 & 0.66 \\
\hline Gender & 0.01 & 0.01 \\
\hline Tenure & 0.36 & 0.34 \\
\hline
\end{tabular}

Sumber: Output smartPLS 3 (2018) 
Menurut Chin (1998), nilai R square diatas 0.67 kuat, antara 0.67 hingga 0.18 moderate, dan dibawah 0.19 lemah.Maka diantara dimensi yang terlibat pada penelitian ini, ada yang terkategori memiliki hubungan yang lemah, moderat dan kuat.Gender termasuk kategori dimensi yang lemah, umur, etnik, pengalaman fungsional dan tenure termasuk kategori moderat dan pendidikan formal termasuk kategori kuat.

\section{Predictive Relevance $\left(\mathrm{Q}^{2}\right)$}

Untuk menghitung Q2 dapat digunakan rumus

$$
\begin{aligned}
& \mathrm{Q}^{2}=1-\left(1-\mathrm{R} 1^{2}\right)\left(1-\mathrm{R} 2^{2}\right) \ldots \ldots\left(1-\mathrm{Rn}^{2}\right) \\
& \mathrm{Q}^{2}=1-(1-0,59)(1-0,51)(1-0,78)(1-0,66)(1-0,01)(1-0,36) \\
& \mathrm{Q}^{2}=0.991
\end{aligned}
$$

Uji ini dilakukan untuk mengetahui kapabilitas prediksi dengan prosedur blinfolding. Menurut (Chin, 1998), jika nilai yang diperoleh adalah antara 0,02 dan 0,15, model tersebut memiliki kemampuan prediksi yang kecil. Jika nilai yang diperoleh adalah antara 0,15 hingga 0,35 , model tersebut memiliki kemampuan prediksi sedang. Akhirnya, jika nilai yang diperoleh di atas 0,35, model tersebut memiliki kemampuan prediksi yang tinggi. Perhitungan terhadap nilai $\mathrm{Q}^{2}$ didapatkan hasil sebesar 0.991 maka model memiliki kapabilitas prediksi yang besar.

\section{Goodness of Fit Index (GoF)}

(Tenenhaus \& Esposito, 2005)merumuskan bahwa nilai GoF kecil ketika itu 0,1, sedang ketika itu 0,25 , dan besar ketika itu 0,38 . Studi ini menghitung nilai GoF dan menemukan bahwa model memiliki nilai GoF yang besar. Ini berarti bahwa model tersebut dapat mewakili fenomena nyata. Nilai GoF dalam SEM dengan PLS dihitung secara manual (Tenenhaus (2004) dengan rumus

$$
\begin{aligned}
& \mathrm{GoF}=\sqrt{\overline{A V E^{2}} \times \overline{\mathrm{R}^{2}}} \\
& \mathrm{GoF}=0.44
\end{aligned}
$$

Penelitian ini menyimpulkan bahwa perhitungan nilai GoF adalah 0,44. Oleh karena itu, disimpulkan bahwa model penelitian dapat menangkap fenomena nyata pada kondisi TMT DiversityBUMN Holding di Indonesia.

\section{Pengujian Hipotesis}

Model struktural dalam SEM-PLS dilakukan dengan proses bootstraping yang menghasilkan nilai t-statistik. Jika nilai t-statistik lebih besar dari t-tabel dengan tingkat kepercayaan 95\% (>1,96), efeknya signifikan. Sedangkan untuk mengetahui seberapa besar pengaruh antar variabel, maka cari tahu nilai loading factor dari sampel asli $(\mathrm{O})$ output. Ini dapat dilihat pada tabel koefisien jalur pada output smartPLS.Berikut disajikan gambar1. Bootstrapping smartPLS. 


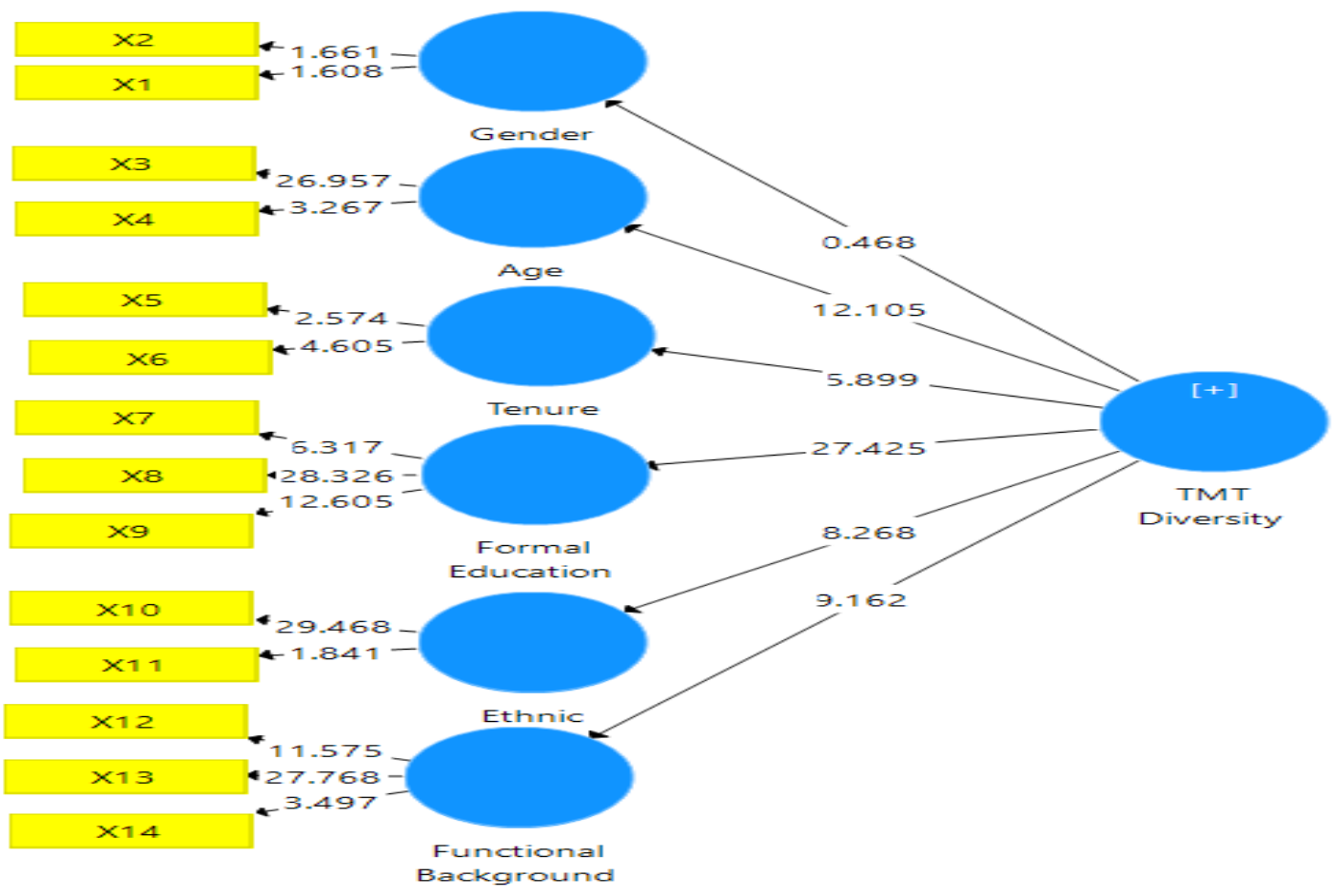

Gambar 1. Bootstrapping SmartPLS

Berdasarkan gambar1. maka diperoleh bahwa sebanyak 5 hipotesis memiliki nilai tvalue diatas 1,96 dan satu hipotesis memiliki tvalue dibawah 1,96. Artinya dari enam dimensi penelitian, sebanyak limadimensiterkonfirmasi memiliki pengaruh positif dan signifikan dalam menyusun TMT Diversity. Sedangkan satu tidak signifikan yakni gender.Untuk meringkas hasil pengujian konfirmasi tersebut berikut disajikan tabel 7. Rangkuman hasil uji konfirmatory dimensi penelitian:

Tabel 5. Rangkuman Hasil Konfirmatory Dimensi Penelitian

\begin{tabular}{lll}
\hline $\mathbf{N o}$ & Konfirmatory Dimensi & Hasil \\
\hline $\mathbf{H}_{\mathbf{1}}$ & TMT Diversity $\boldsymbol{\rightarrow}$ Gender & Ditolak \\
\hline $\mathbf{H}_{\mathbf{2}}$ & TMT Diversity $\boldsymbol{\rightarrow}$ Age & Diterima \\
\hline $\mathbf{H}_{\mathbf{3}}$ & TMT Diversity $\boldsymbol{\rightarrow}$ Tenure & Diterima \\
\hline $\mathbf{H}_{\mathbf{4}}$ & TMT Diversity $\boldsymbol{\rightarrow}$ Formal education & Diterima \\
\hline $\mathbf{H}_{\mathbf{5}}$ & TMT Diversity $\boldsymbol{\rightarrow}$ Ethnic & Diterima \\
\hline $\mathbf{H}_{\mathbf{6}}$ & TMT Diversity $\boldsymbol{\rightarrow}$ Functional Background & Diterima
\end{tabular}

Sumber: Diolah oleh peneliti (2019)

Sedangkan besar koefien jalur untuk masing-masing dimensi bisa dilihat pada Gambar 2 . Algoritme PLS: 


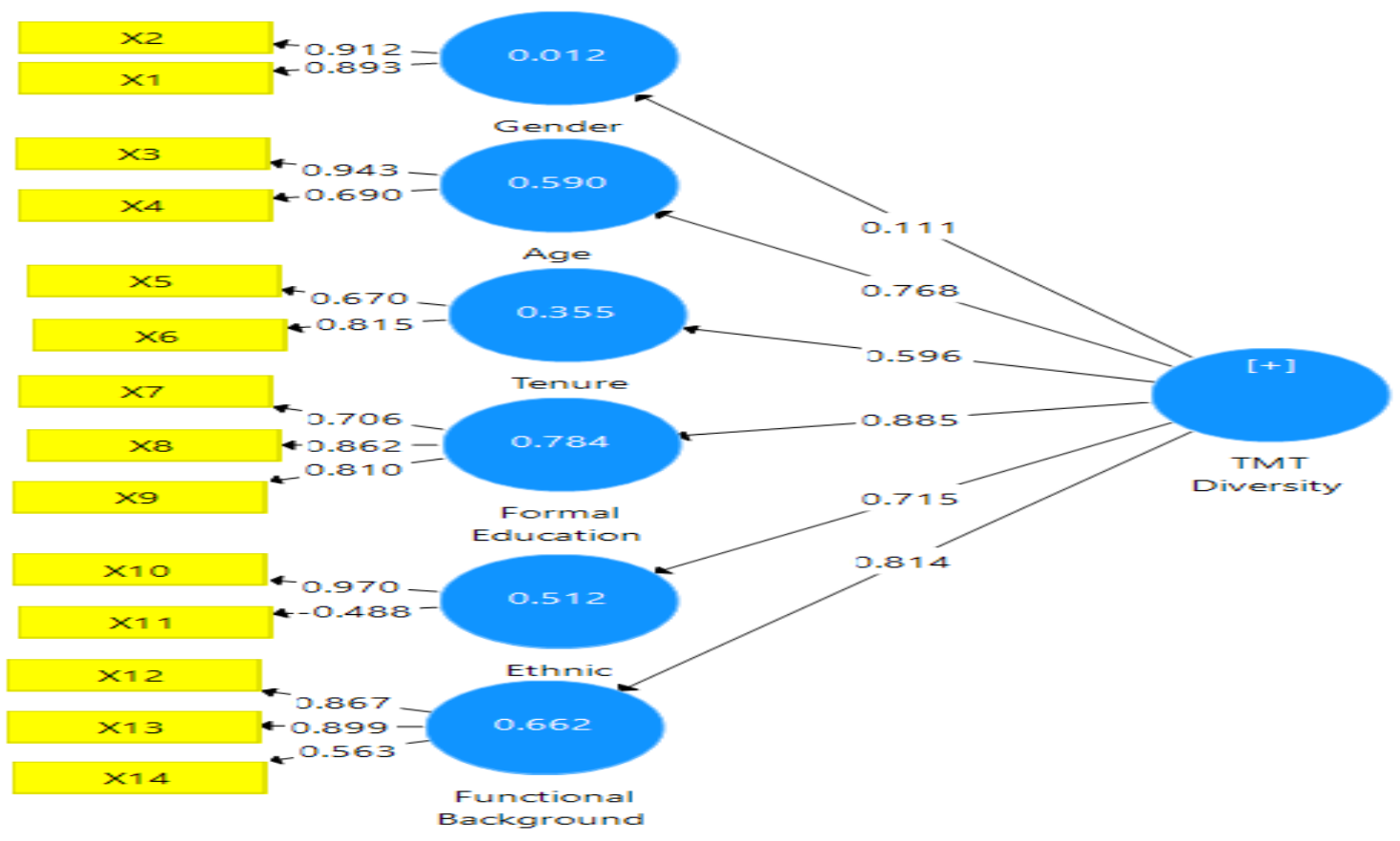

Gambar 2. Algoritme PLS

Berdasarkan hasil running algoritme PLS dan bootstrapping berikut disajikan Table 6. Nilai Algoritme PLS dan Bootstrapping berdasarkan urutan prioritas.

Table 6. Nilai Algoritme PLS dan Bootstrapping berdasarkan urutan prioritas

\begin{tabular}{llcc}
\hline No & Dimensi & Bootstrapping & Algoritme PLS \\
\hline $\mathbf{1}$ & Formal education & 27.425 & 0.885 \\
\hline $\mathbf{2}$ & Functional Background & 9.162 & 0.814 \\
\hline $\mathbf{3}$ & Age & 12.105 & 0.768 \\
\hline $\mathbf{4}$ & Ethnic & 8.268 & 0.714 \\
\hline $\mathbf{5}$ & Tenure & 5.899 & 0.596 \\
\hline $\mathbf{6}$ & Gender & 0.468 & 0.111
\end{tabular}

Sumber: Diolah peneliti (2019)

Berdasarkan hasil running PLS dapat diketahui bahwa terdapat lima dimensi yang signifikan dalam membentuk variable TMT Diversity. Artinya, untuk kasus BUMN Holding di Indonesia terdapat satu dimensi yang tidak signifikan yakni gender sedangkan lima dimensi lain signifikan dalam membentuk variable TMT Diversity. Hasil ini tidak sejalan dengan (Yang \& Wang, 2014) yang menyatakan bahwa gender merupakan bagian dari TMT Diversity. Berikut diberikan penjelasan masing-masing dimensi:

1. Dibanding semua dimensi TMT Diversity, pendidikan formal menjadi dimensi dengan nilai $\mathrm{t}$ statistik yang paling tinggi yakni 27.425. dengan tingkat kepercayaan 95\%. Hal ini menunjukkan bahwa tingkat pendidikan anggota TMT pada BUMN sudah baik. Jika merujuk pada data pendidikan TMT maka dapat diketahui bahwa pendidikan TMT mayoritas magister dan doktor, berikut disajikan tabel 7. pendidikan TMT BUMN Holding di Indonesia. 
JURNAL MANAJEMEN DAN KEUANGAN, VOL 8, NO 3, DESEMBER 2019

Tabel 7. Pendidikan TMT BUMN Holding di Indonesia.

\begin{tabular}{lcc}
\hline Level Pendidikan TMT & Jumlah & Persentase (\%) \\
\hline Doktoral & 3 & 7,5 \\
\hline Magister & 28 & 70 \\
\hline Sarjana & 9 & 22,5 \\
\hline Total & 40 & 100
\end{tabular}

Sumber: Data Primer Penelitian (2019)

Pendidikan anggota TMT merupakan salah satu konstruksi demografi yang paling penting ketika mempertimbangkan keragaman, baik dalam hal levelmaupun bidang studi. Mengikuti asumsi teori upper echelon theory, latar belakang pendidikan dapat dikaitkan dengan informasi dan pengetahuan yang lebih baik dalam tim (D. Li et al., 2008). Selain itu, karena pendidikan formal mencerminkan kemampuan kognitif individu, keragaman dalam latar belakang pendidikan umumnya terkait dengan berbagai perspektif dan set keterampilan manajer puncak(Finkelstein et al., 2009). Oleh karena itu, heterogenitas dalam latar belakang pendidikan dapat meningkatkan pemecahan masalah dan pengambilan keputusan strategis terutama di lingkungan industri yang dinamis dan kompleks seperti BUMN Holding.

2. Penelitian ini membuktikan bahwa dimensi usia pada TMT memiliki nilai t statistik ke-2 terbesar yakni 12.105, signifikan dengan level kepercayaan 95\%.

Keragaman usia dari anggota TMT mencerminkan bahwa mereka telah mengalami lingkungan dan peristiwa sosial, politik, dan ekonomi yang berbeda, yang membentuk berbagai sikap, nilai, dan visi yang sangat mempengaruhi strategi, inovasi, penyesuaian, dan arah perusahaan. Dalam lingkungan yang tidak pasti, berbagai sikap dan nilai dapat meningkatkan kreativitas tim; sehingga tim dengan anggota dari berbagai usia lebih inovatif (Yang \& Wang, 2014). Dengan demikian, konteks hubungan sosial yang lebih luas yang disebabkan oleh heterogenitas usia dapat mendorong perusahaan untuk lebih proaktif mengambil langkah yang lebih strategis. Kisaran usia TMT BUMN Holding antara 30 - 60 tahun dengan persentase sebagai berikut:

Tabel 8. Proporsi usia TMT BUMN Holding

\begin{tabular}{lcc} 
Kategori Umur & Jumlah & Persentase \\
\hline$<\mathbf{3 0}$ & 0 & 0 \\
\hline $\mathbf{3 1 - 4 0}$ & 3 & 7.5 \\
\hline $\mathbf{4 1 - 5 0}$ & 15 & 37.5 \\
\hline $\mathbf{5 1 - 6 0}$ & 22 & 55 \\
\hline$>\mathbf{6 0}$ & 0 & 0 \\
\hline Total & 40 & 100
\end{tabular}

Sumber: Data primer penelitian (2019)

Fakta usia TMT menunjukkan bahwa sebanyak 55\% TMT berumur antara 50-60 tahun; 37,5\% berumur antara 40-50 tahun; dan 7,5 berumur antara 30-40 tahun. Keragaman usia muda-tua terebut sangat penting sebagai penyeimbang dalam pengambilan keputusan strategis. Keragaman umur diharapkan dapat meningkatkan berbagai perspektif tentang isu-isu strategis menghadapi 
suatu perusahaan, sehingga merangsang pertimbangan perubahan. Dengan demikian, umur mempengaruhi perspektif pengambilan keputusan dan pilihan strategis. Anggota tim yang lebih tua jarang mengambil risiko dan mungkin lebih enggan untuk berubah, sementara anggota TMT yang lebih muda cenderung mendukung keputusan yang berisiko serta memiliki tingkat pendidikan yang lebih tinggi (Wiersema \& Bantel, 2010). Selain itu, manajer yang lebih muda lebih cenderung untuk berpartisipasi dalam strategi inovatif yang mengarah pada pertumbuhan perusahaan (Barker, Patterson, \& Mueller, 2001).Kategori umur yang berbeda menentukan pilihan keputusan yang berbeda. Heterogenitas umur meningkatkan keragaman pandangan terhadap isu-isu strategis (Yang \& Wang, 2014). Dengan demikian, konteks hubungan sosial yang lebih luas yang disebabkan oleh heterogenitas umur dapat mendorong perusahaan untuk lebih proaktif mengambil langkah yang lebih strategis.

3. Selanjutnya, penelitian empiris juga menemukan heterogenitas latar belakang fungsional atau keragaman dalam pengalaman fungsional berhubungan secara positif dengan adaptasi dan perubahan strategi. Penelitian ini membuktikan bahwa latar belakang fungsional memiliki nilai $t$ statistik sebesar 9.162. Heterogenitas latar belakang profesional dapat membawa keterampilan teknis, hukum, dan manajemen TMT dan kemampuan untuk membentuk perspektif baru dan informasi yang beragam. Kombinasi heterogenitas latar belakang profesional membawa ide-ide baru untuk mencegah pemikiran yang bersifat jangka pendek, meningkatkan kemampuan pemecahan masalah yang inovatif dan memecahkan masalah kompleks yang tidak standar. Tim eksekutif dapat dilihat sebagai alat pengolah informasi(Harrison \& Klein, 2007).

Pengalaman profesional TMT BUMN holding secara garis besar menunjukkan 2 (dua) hal; ada yang punya pengalaman dengan perusahaan yang sama $(62,5 \%)$, ada yang berpengalaman dengan perusahaan yang sama sekali berbeda (37,5\%); misalnya direktur PT. Inhutani II yang sebelumnya merupakan direktur keuangan Biofarma; direktur keuangan Perum Perhutani sebelumnya Kepala Divisi Mass Banking Bank BRI; Direktur Keuangan PTPN. XII sebelumnya merupakan VP Bank Mandiri; Direktur Operasional PTPN. XI sebelumnya adalah direktur kampus LPP Yogjakarta; Dirut PTPN. IX sebelumnya adalah dirut perum bulog; direktur komersil PTPN. VIII sebelumnya adalah pimpinan wilayah BNI Sumsel.

Tabel 9. Pengalaman Fungsional TMT

\begin{tabular}{lcc}
\hline Pengalaman Profesional TMT & Jumlah & Persentase \\
\hline Pengalaman di perusahaan yang sama & 25 & 62.5 \\
\hline Pengalaman diperusahaan yang berbeda & 15 & 37.5 \\
\hline Total & 40 & 100 \\
\hline
\end{tabular}

Sumber: Diolah dari data primer hasil penelitian (2019)

Penelitian empiris mengklaim bahwa pengalaman profesional anggota TMT mewakili proksi keahlian dan kemampuan manajerial yang baik (Carpenter et al., 2004; Carpenter \& Sanders, 2002; Graffin, et al., 2011). Secara khusus, dua aspek yang berbeda dalam hal pengalaman 
professional; di satu sisi, pengalaman sebelumnya anggota TMT dalam industri di mana perusahaan beroperasi secara dominan dan, di sisi lain, pengalaman yang diperoleh dari industri lain. Kedua aspek ini diharapkan membawa beberapa manfaat bagi TMT dan organisasi secara umum untuk meningkatkan kinerja.

4. Penelitian ini membuktikan bahwa etnik merupakan dimensi penyusun TMT Diversity dengan nilai $\mathrm{t}$ statistik sebesar 8.268 dengan tingkat kepercayaan sebesar 5\%.Etnik lazimnya diukur berdasarkan suku orang tua yang disertai dengan berbagai norma, kumpulan informasi, tingkat pengetahuan dan kemampuan (Morgan, J. and Vardy, 2009). Variasi ini memengaruhi pembentukan dan kerja tim. Keragaman etnis akan menguntungkan kerja tim karena kumpulan keterampilan dan pengetahuan yang lebih beragam yang mengarah pada pelengkap dan pembelajaran bersama. Misalnya, karena saling melengkapi dan kesempatan belajar, tim yang beragam secara etnis dikaitkan dengan lebih banyak kreativitas dan inovasi (Alesina, A. and La Ferrara, 2005; Ozgen, C., Nijkamp, P., and Poot, n.d.). Jika memperhatikan komposisi etnik TMT BUMN Holding maka akan didapatkan sebaran etnis yang kurang merata yakni 72,5\% etnik Jawa, 15\% etnik Minang, 7,5\% etnik Batak, 2,5\% etnik Sunda, dan 2,5\% etnik Madura. Menurut data. Dari total 40 responden diwakili oleh lima etnis dari ratusan etnis se Indonesia. Berikut disajikan komposisi tabel 10 Komposisi etnis TMT BUMN Holding.

Tabel 10. Komposisi etnis TMT BUMN Holding.

\begin{tabular}{lcc}
\hline Suku & Jumlah & Persentase \\
\hline Jawa & 29 & 72.5 \\
\hline Minang & 6 & 15 \\
\hline Batak & 3 & 7.5 \\
\hline Sunda & 1 & 2.5 \\
\hline Madura & 1 & 2.5 \\
\hline Jumlah & 40 & 100
\end{tabular}

Sumber: Data Primer Penelitian (2019)

5. Masa jabatan. salah satu karakteristik yang paling banyak dinilai dalam literatur TMTadalah masa jabatan CEO di dalam organisasi (Hambrick, 2016). Studi menunjukkan bahwa CEO memainkan peran kunci dalam membuat keputusan pemilihan TMT (Chen \& Nadkarni, 2017; Finkelstein et al., 2009). Penelitian tentang saling melengkapi CEO-TMT menunjukkan bahwa CEO cenderung memilih anggota TMT yang melengkapi diri mereka dalam karakteristik pengalaman (Hambrick, 2016).Berdasarkan logika saling melengkapi, CEO yang memiliki masa jabatan lama memilih eksekutif yang dapat mempromosikan pembaruan organisasi melalui pengalaman mereka dari luar perusahaan dan karakteristik mereka yang beragam. Untuk memungkinkan adaptasi organisasi, CEO dengan masa kerja yang lama cenderung mempekerjakan eksekutif eksternal yang berbeda dengan manajer puncak yang berkuasa dalam atribut demografis. Eksekutif eksternal yang berbeda dapat bertindak sebagai pembatas terhadap tim incumbent saat ini melalui karakteristik dan pengalaman mereka yang berbeda dari luar organisasi (Finkelstein et al., 2009; Nielsen, 2010a, 
2010b). Pemilihan eksekutif eksternal yang berbeda dapat mengimbangi kurangnya pengetahuan eksekutif internal yang telah lama berkuasa, dan membantu perusahaan untuk meningkatkan pembaruan organisasi dan adaptasi lingkungan (A J Ward, et al., 2007).

Berdasarkan informasi masa jabatan TMT, terdapat keragaman masa jabatan yang merata yakni < 1 tahun $27,5 \%$; $1-2$ tahun $27,5 \%$; $2-3$ tahun $32,5 \% ; 3-4$ tahun $5 \%$; $4-5$ tahu $5 \%$ dan $>5$ tahun $2,5 \%$.

Tabel 11. Keragaman masa jabatan

\begin{tabular}{lcc}
\hline Lama Menjabat & Jumlah & Persentase \\
\hline$<1$ tahun & 11 & 27.5 \\
\hline $1-2$ tahun & 11 & 27.5 \\
\hline 2 - 3 tahun & 13 & 32.5 \\
\hline 3 tahun & 2 & 5 \\
\hline 4 - tahun & 2 & 5 \\
\hline$>5$ tahun & 1 & 2.5 \\
\hline Total & 40 & 100
\end{tabular}

Sumber: Data Primer Penelitian (2019)

6. Gender. Manajemen dan literatur psikologi sosial menyarankan bahwa manajer senior pria dan wanita berperilaku berbeda, dan dapat mempengaruhi strategi perusahaan secara berbeda (Klenke, 2003).Eksekutif pria dan wanita merasakan risiko secara berbeda; eksekutif laki-laki lebih proaktif, lebih tertarik pada risiko, dan lebih mungkin menunjukkan kepercayaan berlebihan (P.-Y. Li, 2017). Dengan demikian, eksekutif laki-laki lebih berani dan menerapkan kegiatan strategis wirausaha yang relatif lebih agresif (Yang \& Wang, 2014).Korelasi positif antara keragaman gender TMT lebih signifikan di pasar yang sangat kompetitif dan dengan tata kelola eksternal yang tidak sempurna. Sedangkan karakteristik BUMN yang didukung highregulationbukanlah termasuk perusahaan dengan pasar persaingan seperti pasar persaingan sempurna. Ketika perusahaanperusahaan sejenis bergabung menjadi satu holding dan pemain tunggal dipasar tersebut maka BUMN holding lebih layak disebut sebagai pelaku di pasar monopoli. Maka proporsi TMT yang diperlukan bukan lagi sebatas keberanian tapi harus bisa mengelola perusahaan dalam jangka panjang.Saat ini, realitas proporsi TMT BUMN Holding menunjukkan bahwa 92,5\% TMT lakilaki dan $7,5 \%$ perempuan.

Tabel 12. Proporsi TMT berdasarkan Jenis Kelamin

\begin{tabular}{lccc} 
Jenis Kelamin & Jumlah & & Persentase \\
\hline Laki-laki & 37 & 92.5 & \\
\hline Perempuan & 3 & 7.5 & \\
\hline Total & 40 & 100
\end{tabular}

Sumber: Data Primer Penelitian (2019)

Berdasarkan data tersebut terlihat proporsi TMT laki-laki $(92,5 \%)$ dan perempuan $(7,5 \%)$. Komposisi tersebut tidak berimbang, pria lebih dominan daripada wanita. Meski begitu, komposisi tersebut sejalan dengan komposisi kepemimpinan perusahaan dunia, data menunjukkan bahwa kepemimpinan bisnis dunia didominasi oleh pria meski ada trend kepemimpinan wanita 
diperusahaan meningkat. Dalam 15 tahun terakhir, bagian wanita dari posisi pejabat perusahaan di perusahaan-perusahaan Fortune 500 telah meningkat dari 8,7 menjadi 15,7 persen; kursi dewan dari 9,6 hingga 15,2 persen; dan posisi CEO dari 0,2 persen menjadi 3,0 persen (Catalyst 2010).Kondisi ini memberikan suatu pemahaman bahwa jenis kelamin bukanlah pertimbangan utama ketika melakukan penunjukkan dan pengangkatan TMT. Pria dan wanita sama-sama bisa menjabat sebagai TMT di perusahaan BUMN Holding dengan peluang yang sama besar. Andai tidak ada lelaki yang memiliki kompetensi maka perempuan dapat memangku jabatan sebagai TMT. Hal ini karena keberagaman jenis kelamin tidak signifikan dalam membentuk konstruk TMT diversity. Seluruh anggota TMT dapat berjenis kelamin pria, bisa juga terdiri dari pria dan wanita atau juga bisa seluruhnya berjenis kelamin wanita.

\section{KESIMPULAN DAN SARAN}

\section{Kesimpulan}

Keragaman Top Manajemen Tim (TMT) merupakan kekuatan suatu organisasi bisnis dalam mengambil keputusan strategis secara tepat. Dalam artikel ini, kami menguji TMTdiversitypada BUMN Holding di Indonesia. Hasil pengujian pada model TMT diversity ditemukan bahwa lima dari enam dimensi membentuk konstruk TMT diversity secara signifikan. Satu dimensi tidak signifikan yakni gender. Lima dimensi dominan dan direkomendasikan yang membentuk konstruk TMT Diversity pada BUMN Holding adalah usia, etnik, masa jabatan, pendidikan formal dan pengalaman fungsional.

\section{Implikasi}

Artikel ini memiliki implikasi bagi para pembuat kebijakan untuk menetapkan dan memilih Top Leader berdasarkan pertimbangan dimensi yang signifikan tersebut. Gender sebagai satu-satunya dimensi yang tidak signifikan menunjukkan bahwa perbedaaan kelamin bukanlah persoalan dalam penetapan TMT diversity. Artinya, pada kasus BUMN Holding, tidak akan menimbulkan persoalan jika komposisi TMT jenis kelamin seragam. Sedangkan yang harus beragam adalah dimensi yang signifikan yakni usia, etnik, masa jabatan, pendidikan formal dan pengalaman fungsional. Mengingat pentingnya peran BUMN dalam proses pembangunant nasional, maka setiap kebijakan penentuan TMT, harus mempertimbangkan lima dimensi dominan tersebut.membentuk konstruk TMT Diversity, yaitu usia, etnik, masa jabatan, pendidikan formal dan pengalaman fungsional.

\section{Keterbatasan studi}

Penelitian ini memiliki keterbatasan lokus penelitian yakni hanya meneliti pada level Top level manejer untuk menganalisis keragaman TMT. Jika melibatkan level manejer menengah dan bawah maka akan diperoleh perspektif yang berbeda dalam menilai keragaman TMT. Untuk agenda riset 
selanjutnya penulis merekomendasikan untuk melakukan penelitian dengan lokus penelitian yang lebih luas bukan hanya pada level Top manejer tapi juga middle level manager dan low level manager.

\section{REFERENSI}

Alesina, A. and La Ferrara, E. 2005. Ethnic Diversity and Economic Performance. Journal of Economic Literature. Vol. 43. No.3. Page: 762-800.

Bakas, F. E. 2017. 'A Beautiful Mess': Reciprocity and Positionality in Gender and Tourism Research. Journal of Hospitality and Tourism Management, Vol.33, Page: 126-133. https://doi.org/10.1016/j.jhtm.2017.09.009

Barker, V. L., Patterson, P. W., \& Mueller, G. C. 2001. Organizational Causes and Strategic Consequences of The Extent of Top Management Team Replacement During Turnaround Attempts. Journal of Management Studies. Vol. 38. No.2. Page: 235-269. https://doi.org/10.1111/1467-6486.00235

Camelo, C., Fernández-alles, M., Hernández, A. B., \& Fernández-Alles, M. 2017. Strategic Consensus, Top Management Teams, and Innovation Performance. International Journal of Manpower Journal of Management Development European Journal of Innovation Management. Vol. 31. No.19. Page: 678-695. Retrieved from https://doi.org/10.1108/01437721011073373705

Carpenter, M. A., Geletkancz, M. A., \& Sanders, W. G. 2004. Upper Echelons Research Revisited: Antecedents, Elements, and Consequences of Top Management Team Composition. Journal of Management. https://doi.org/10.1016/j.jm.2004.06.001

Carpenter, M. A., \& Sanders, G. 2002. Top Management Team Compensation: The Missing Link Between CEO PAy and Firm Performance? Strategic Management Journal. https://doi.org/10.1002/smj.228

Certo, S. T., Lester, R. H., Dalton, C. M., \& Dalton, D. R. 2006. Top Management Teams, Strategy and Financial Performance: A Meta-Analytic Examination. Journal of Management Studies, Vol. 43 No. 4, Page: 813-839. https://doi.org/10.1111/j.1467-6486.2006.00612.x

Chen, J., \& Nadkarni, S. 2017. It's about Time! CEOs' Temporal Dispositions, Temporal Leadership, and Corporate Entrepreneurship. Administrative Science Quarterly, Vol. 62 No.1, Page: 31-66. https://doi.org/10.1177/0001839216663504

Chin, W. W. 1998. The Partial Least Squares Approach to Structural Equation Modeling. New Jersey: Psychology Press.

Creswell, J. W. 2014. Research Design: Qualitative, Quantitative and Mixed Methods Approaches (4th ed.). London: Sage.

Finkelstein, S., Hambrick, D. C., \& Cannella, A. A. 2009. Strategic Leadership: Theory and Research on Executives, Top Management Teams, and Boards. Theory and Research On Executives, Top Management Teams, and Boards. Retrieved from http://www.worldcat.org/oclc/224445907

Gallén, T. 2009. Top Management Team Composition and Views of Viable Strategies. Team Performance Management, Vol. 15 No. 7/8, Page: 326-342. https://doi.org/10.1108/13527590911002113

Ghozali, I. 2014. SEM Metode Alternatif dengan Menggunakan Partial Least Squares (PLS). Semarang: Badan Penerbit Universitas Diponegoro.

Ghozali, Imam. 2011. Aplikasi Analisis Multivariate Dengan Program SPSS. Semarang: Badan Penerbit Universitas Diponegoro.

Graffin, S. D., Carpenter, M. A., \& Boivie, S. 2011. What's All That (Strategic) Noise? Anticipatory Impression Management In CEO Succession. Strategic Management Journal, Vol. 32 No. 7 , Page: 748-770. https://doi.org/10.1002/smj.906

Harrison, D. A., \& Klein, K. J. 2007. What's The Difference? Diversity Constructs as Separation, Variety, or Disparity in Organizations. Academy of Management Review, Vol. 32 No. 4, Page: 1199-1228. https://doi.org/10.5465/AMR.2007.26586096

Hitt, M. A., Ireland, R. D., \& Hoskisson, R. E. 2016. Strategic Management: Competitiveness \& Globalization: Concepts and Cases, Case 17 Starbucks Corporation: The New S-Curves. 
https://doi.org/10.1017/CBO9781107415324.004

Jurkus, A., Park, J., \& Woodard, L. 2011. Women in Top Management and Agency Costs. Journal of Business Research, Vol. 64 No. 2, Page: 180-186. https://doi.org/10.1016/j.jbusres.2009.12.010

Kilduff, M., Angelmar, R., \& Mehra, A. 2000. Top Management-Team Diversity and Firm Performance: Examining the Role of Cognitions. Organization Science, Vol. 11 No. 1, Page: 21-34. https://doi.org/10.1287/orsc.11.1.21.12569

Klenke, K. 2003. Gender Influences in Decision-Making Processes in Top Management Teams. Management Decision, Vol. 41 No. 10, Page: 1024-1034. https://doi.org/10.1108/00251740310509553

Li, D., Eden, L., Hitt, M. A., Ireland, R. D., Sebaa, A. A., Wallace, J., Raver, J. L. 2008. Strategic Consensus, Top Management Teams, and Innovation Performance. Leadership \& Organization Development Journal, Vol. 29 No. 4, Page: 340-358. https://doi.org/10.1108/01437721011073373

Li, P.-Y. 2017. The Impact of The Top Management Teams' Knowledge and Experience on Strategic Decisions and Performance. Journal of Management \& Organization, Vol. 23 No. 04, Page: 504-523. https://doi.org/10.1017/jmo.2016.24

Ling, Y., Wei, L., Klimoski, R. J., \& Wu, L. 2015. Benefiting From CEO's Empowerment of Tmts: Does CEO-TMT Dissimilarity Matter? Leadership Quarterly, Vol. 26 No. 6, Page: 1066-1079. https://doi.org/10.1016/j.leaqua.2015.07.006

Morgan, J. and Vardy, F. 2009. Diversity in The Workplace. The American Economic Review, Vol. 99 No. 1, Page: 472-485.

Naresh, M. 2010. Marketing Research: An Applied Orientation (6* edition). Pearson Education.

Nielsen, S. 2010a. Top Management Team Diversity: a Review of Theories and Methodologies. International Journal of Management Reviews. https://doi.org/10.1111/j.14682370.2009.00263.x

Nielsen, S. 2010b. Top Management Team Internationalization and Firm Performance The Mediating Role of Foreign Market Entry, 185-206. https://doi.org/10.1007/s11575-010-0029-0

Park, S., \& Cho, Y. J. 2014. The Influence of Executive Selection Factors on the Performance of Public Sector Organizations in Korea. Public Performance \& Management Review, Vol. 37 No. 3, Page: 412-440. https://doi.org/10.2753/PMR1530-9576370304

Rencana Strategis Deputi Bidang Usaha Energi, Logistik, Kawasan, D. P. (n.d.). No Title. Kementerian Badan Usaha Milik Negara Republik Indonesia.

Sugiyono. 2010. Statistika Untuk Penelitian. Bandung: Alfabeta.

Tenenhaus, M., \& Esposito, V. 2005. PLS Path Modeling. Computational Statistics \& Data Analysis, Vol. 48, Page: 159-205. https://doi.org/10.1016/j.csda.2004.03.005

Van Knippenberg, D., Dawson, J. F., West, M. A., \& Homan, A. C. 2011. Diversity Faultines, Shared Objectives, and Top Management Team Performance. Human Relations, Vol. 64 No. 3, Page: 307-336. https://doi.org/10.1177/0018726710378384

Ward, A. J., Lankau, M. J., Amason, A. C., Sonnenfeld, J. A., \& Agle, B. R. 2007. Improving The Performance of Top Management Teams. Mit Sloan Management Review, Vol. 48 No. 3, 85-+. Retrieved from wos:000245862300014

Wetzels, M., Odekerken-Schroder, G., \& van Oppen, C. 2009. Using PLS Path Modelling for Assessing Hierarchical Construct Models: Guidelines and Empirical Illustration. Management Information Systems Research Center, Vo. 33 No. 1, Page: 177-195. 